\title{
$\mathrm{Al}^{3+}$ 와 $\mathrm{Y}^{3+}$ 동시치환 $\mathrm{SnO}_{2}$ 투명전극 박막의 전기적 특성

\author{
김근우 ${ }^{1}$, 서용준 ${ }^{1}$, 성창훈 ${ }^{1}$, 박근영 $^{1}$, 조호제 ${ }^{1}$, 허시내 ${ }^{1}$, 구본흔 $^{1, a}$ \\ 1 창원대학교 나노신소재공학부
}

\section{Electrical Properties of $\mathrm{Al}^{3+}$ and $\mathrm{Y}^{3+} \mathrm{Co}$-doped $\mathrm{SnO}_{2}$ Transparent Conducting Films}

\author{
Geun-Woo Kim ${ }^{1}$, Yong-Jun Seo ${ }^{1}$, Chang-Hoon Sung ${ }^{1}$, Keun-Young Park ${ }^{1}$, Ho-Je Cho ${ }^{1}$, \\ $\mathrm{Si}^{-\mathrm{Nae}} \mathrm{Heo}^{1}$, and Bon Heun Koo ${ }^{1, \mathrm{a}}$ \\ ${ }^{1}$ School of Nano\&Advanced Materials Engineering, Changwon National University, \\ Changwon 641-773, Korea
}

(Received July 31, 2012; Revised August 24, 2012; Accepted August 29, 2012)

\begin{abstract}
Transparent conducting oxides (TCOs) have wide range of application areas in transparent electrode for display devices, Transparent coating for solar energy heat mirrors, and electromagnetic wave shield. $\mathrm{SnO}_{2}$ is intrinsically an $\mathrm{n}$-type semiconductor due to oxygen deficiencies and has a high energy-band gap more than $3.5 \mathrm{eV}$. It is known as a transparent conducting oxide because of its low resistivity of $10^{-3} \Omega \cdot \mathrm{cm}$ and high transmittance over $90 \%$ in visible region. In this study, co-doping effects of $\mathrm{Al}$ and $\mathrm{Y}$ on the properties of $\mathrm{SnO}_{2}$ were investigated. The addition of $\mathrm{Y}$ in $\mathrm{SnO}_{2}$ was tried to create oxygen vacancies that increase the diffusivity of oxygen ions for the densification of $\mathrm{SnO}_{2}$. The addition of $\mathrm{Al}$ was expected to increase the electron concentration. Once, we observed solubility limit of $\mathrm{SnO}_{2}$ single-doped with $\mathrm{Al}$ and $\mathrm{Y}$. $\left\{(\mathrm{x} / 2) \mathrm{Al}_{2} \mathrm{O}_{3}+(\mathrm{x} / 2) \mathrm{Y}_{2} \mathrm{O}_{3}\right\}-\mathrm{SnO}_{2}$ was used for the source of $\mathrm{Al}$ and $\mathrm{Y}$ to prevent the evaporation of $\mathrm{Al}_{2} \mathrm{O}_{3}$ and for the charge compensation. And we observed the valence changes of aluminium oxide because generally reported of valence changes of aluminium oxide in Tin - Aluminium binary system. The electrical properties, solubility limit, densification and microstructure of $\mathrm{SnO}_{2}$ co-doped with $\mathrm{Al}$ and $\mathrm{Y}$ will be discussed.
\end{abstract}

Keywords: TCO, Co-doping, Densification, PLD, Thin film

\section{1. 서 론}

최근 투명 전도성 산화물 (transparent conducting oxide, TCO)은 FPD (flat panel display), solar

a. Corresponding author; bhkoo@changwon.ac.kr battery, gas sensor, touch panel sensor 등 다양한 산업에서 투명전극으로 광범위하게 사용되어져 왔다 [1,2]. 현재까지 국내의 TCO 관련 연구는 광전자분야 에서 가장 널리 사용되고 있는 ITO (Sn doped $\left.\mathrm{In}_{2} \mathrm{O}_{3}\right)$ 에 치중되어 있으며 관련 연구도 거의 디스플레 이 맞춤형 연구 개발이 주류를 이루어왔다 [3,4]. 비 록 $\mathrm{ITO}$ 가 전기 전도성이 우수하고 동시에 가시광선 
영역에서의 투과율도 $80 \%$ 이상으로 전기적, 광학적 특성이 우수하다는 장점을 가지고 있으나, 디스플레 이의 대형화에 따라 ITO 물성의 저 저항화의 한계와, 원료 물질인 인듐 (In)의 수급량 부족으로 인한 문제 점이 제기되고 있다. 공급량이 한정되어 있고, 2004년 도에 이미 전 세계에서 생산되는 인듐의 절반 이상이 $\mathrm{FPD}$ 용으로 소진되고 있으며 가격이 귀금속에 견줄 정도로 고가일 뿐만 아니라, 가격 안정성도 없는 단 점 때문에 인듐을 전혀 사용하지 않는 대체 재료의 개발이 시급한 상황이다 [5]. ITO를 대체할 재료 중 에 $\mathrm{ZnO}$ 계 박막의 경우 우수한 광학적, 전기적 특성을 가지고 있으나 산, 염기에 취약하고 기계적 성질이 우수하지 못하다. 반면 $\mathrm{SnO}_{2}$ 계 박막의 경우 제조 원 가가 ITO에 비하여 월등히 저렴하고 내화학성과 내 마모성이 우수하면서도, 가시광 영역에서의 광투과율 이 $80 \%$ 이상으로 좋다는 점으로 $\mathrm{ITO}$ 를 대체할 재료 로 주목을 받고 있다. 하지만 순수한 $\mathrm{SnO}_{2}$ 박막의 경 우 비저항 값이 $10^{-2} \sim 10^{-1} \Omega \cdot \mathrm{cm}$ 정도로 높은 문제점 으로 ITO와 같은 투명전극으로 사용하기 위해서는 전기전도도를 향상시킬 필요가 있다 [6-9]. $\mathrm{SnO}_{2}$ 박 막은 $3.5 \mathrm{eV}$ 이상의 넓은 광학적 밴드 갭을 갖는 n-type 반도체로서 [10]. 가시광 스펙트럼 영역에서 투명하며 높은 전기 전도성을 가지므로 투명전극재료 [11-15], 디스플레이 소자 [16], 태양전지 [17], 뿐만 아니라 반도체 가스센서 $[18,19]$ 등에도 중요한 소재 로 사용되고 있다. $\mathrm{SnO}_{2}$ 의 전기전도성은 $\mathrm{Tin}$ 과 oxygen 사이의 비화학양론성에 기인하는 데 [19] 실제 로 비화학 양론성을 이용하여 전기 전도성을 제어한 다는 것이 매우 어려우나 적절한 dopant를 첨가하여 $\mathrm{SnO}_{2}$ 자체의 높은 광학적 투과도를 유지하면서 전기 전도성을 더 높일 수 있어 보다 우수한 투명전극 재 료로서의 활용이 기대되어 진다 [20]. Dopant 물질로 는 $\mathrm{Bi}, \mathrm{Al}, \mathrm{Y}, \mathrm{Ga}, \mathrm{Sb}$ 등의 원소를 소량 치환 첨가시 킴으로써 비저항을 ITO 박막 수준으로 낮추려는 많 은 연구가 진행 되어왔다 [21-24].

또한 양이온 자리에 다른 3 가의 원소를 동시 치환 하게 되면 고용 영역의 확대를 기대할 수 있어 동시 치환 효과에 의한 특성 향상에 관한 연구도 현재 활 발히 진행되어지고 있다. 이에 관한 이론적 배경은 다음과 같이 설명되어질 수 있다. 변형에너지의 감소 의 영향으로 고용 영역이 확대가 이루어진다. 특히, 변형에너지의 관점에서 봤을 때, $\mathrm{Sn}^{4+}(0.071 \mathrm{~nm})$ 의 자 리에 $\mathrm{Al}^{3+}(0.051 \mathrm{~nm})$ 과 $\mathrm{Y}^{3+}(0.09 \mathrm{~nm})$ 를 동시에 치환하 게 되면 $\mathrm{Sn}^{4+}$ 자리에 모상의 이온 반경보다 큰 것 $\left(\mathrm{Y}^{3+}\right)$
과 작은 것 $\left(\mathrm{Al}^{3+}\right)$ 이 동시에 들어가게 된다. 이것은 동 시 첨가를 했을 때 서로 간의 상쇄효과가 나타나서 결과적으로 변형에너지의 감소를 이끌어낼 수 있다. $\mathrm{SnO}_{2}$ 에 불순물을 첨가하게 되면 서로 간에 압축응력 과 인장응력이 생기게 된다. 하지만 동시 첨가로 인 해서 서로 간의 반발력이 완화되어 각각 첨가하였을 때 나타나는 응력을 줄여주기 때문에 변형 에너지의 감소로 이어지게 된다. 즉, 앞에서 언급한 '변형에너 지의 감소'와 영향으로 추가적인 에너지의 낭비가 없 어지고, 이로 인해서 고용 영역의 확대가 이루어진다 고 할 수 있다 [25-27]. $\mathrm{SnO}_{2}$ 계에서 대표적으로 알려 진 물질은 원소 $\mathrm{F}$ 인데 $\mathrm{FTO}$ 는 양이온 자리 치환이 아 닌 음이온 자리 치환을 유도하여 특성개발을 하는 것 이고 $\mathrm{Al}$ 과 $\mathrm{Y}$ 는 양이온자리 치환을 목표로 동시 치환 하여 이온반경 조절로 인한 스트레스 감소 즉, 결함감 소를 유도하여 특성향상을 목적으로 $\mathrm{Al}$ 과 $\mathrm{Y}$ 를 $\mathrm{SnO}_{2}$ 에 동시 치환하여 이온반경을 주격자 이온 $\left(\mathrm{Sn}^{4+}\right)$ 과의 이온 반경비를 유사하게 조절함으로써 변형에너지를 보다 감소시켜 고용영역을 확대하기 위해 연구를 진 행하였다.

따라서 본 연구에서는 $\mathrm{SnO}_{2}$ 에 양이온 3 가 원소 ( $\mathrm{Bi}, \mathrm{Al}, \mathrm{Y}, \mathrm{Ga}, \mathrm{Sb}$ )등을 co-doping 후 PLD (pulsed laser deposition)를 이용하여 투명전극의 특성을 만족 하는 박막을 제작하여 동시치환 효과를 규명하고, 투 명전극으로서의 전기적 특성을 향상시키기 위해 박막 의 전기적 특성을 심도있게 고찰하였다.

\section{2. 실험 방법}

본 실험에서는 PLD (pulsed laser deposition)법을 사용하였다. 이는 물리적 증착법의 하나로 단파장의 레이저 pulse로 target 표면을 융제 (ablation)시킨 후, 융제된 target의 구성요소를 기판위에 증착시켜 박막 층을 형성시키는 방법이다. 이러한 PLD법의 가장 큰 장점은, 다성분계 산화물 target을 사용할 때, 화학양 론이 우수한 막을 형성시킬 수 있다는 점이며, 또한 target에서 방출되는 입자들의 운동에너지가 200 $400 \mathrm{eV}$ 로 매우 높아 비교적 낮은 기판온도에서 결정 화가 가능하고 박막의 증착속도도 빠르다. 또 다른 장점은 다수의 target을 회전 홀더에 장착하여, 종류 가 다른 target을 분위기의 변화 없이 연속적으로 증 착할 수 있으므로, 상대적으로 깨끗한 계면을 가지는 이종구조나 초격자를 성장시킬 수 있다는 점이다. 본 
실험에서는 $\mathrm{PLD}$ 법을 사용하여 유리기판 위에 $\mathrm{Al}_{2} \mathrm{O}_{3}$ : $\mathrm{Y}_{2} \mathrm{O}_{3}-\mathrm{SnO}_{2}$ 박막을 증착하였으며. $\mathrm{PLD}$ 용 타겟은 일 반적인 산화물 제작방법인 고상소결법을 사용하였다. $\mathrm{Al}_{2} \mathrm{O}_{3}: \mathrm{Y}_{2} \mathrm{O}_{3}-\mathrm{SnO}_{2}$ 의 $\mathrm{Al}_{2} \mathrm{O}_{3}$ 과 $\mathrm{Y}_{2} \mathrm{O}_{3}$ 의 비율을 $0: 6,1$ $: 5,2: 4,3: 3,4: 2,5: 1,6: 0$ 으로 변화시켜 타겟을 제작하였다. 제작 방법 및 순서는 아래와 같다.

$\mathrm{Al}_{2} \mathrm{O}_{3}$ 와 $\mathrm{Y}_{2} \mathrm{O}_{3}$ 및 $\mathrm{SnO}_{2}$ raw powder (순도 $99.99 \%$ ) 를 폴리에틸렌 병에 $\mathrm{ZrO}$ ball과 함께 ethanol을 용매 로 하여 24시간 동안 ball milling을 통해서 습식으로 혼합하였다. 이 때, powder: ball : ethanol의 부피 비는 $1: 1: 2$ 로 하였으며, 혼합된 분말은 $80^{\circ} \mathrm{C}$ 의 dry-oven 에서 48시간 동안 완전 건조하였다. 건조된 분말은 10 $\mathrm{mm}$ mold를 사용하여 원통형으로 가성형을 한 다음, $100 \mathrm{MPa}$ 의 압력으로 성형하였다. 일반 고온 열처리 로를 사용하여 $5^{\circ} \mathrm{C} / \mathrm{min}$ 으로 승온 속도를 고정하여 수 평 tube-furnace에 넣어 $1,250^{\circ} \mathrm{C}$ 에서 10 시간 동안 대 기 분위기에서 소결하였으며 냉각하였다. 제작된 PLD용 타겟을 사용하여 박막 제작 시 박막의 두께는 $300 \mathrm{~nm}$ 고정하였으며, 산소분압과 기판온도를 실험 변수로 두고 실험을 수행하였다.

\section{3. 결과 및 고찰}

그림 1 은 $\mathrm{SnO}_{2}$ 에 3 가 원소 $\left(\mathrm{Bi}_{2} \mathrm{O}_{3}, \mathrm{Al}_{2} \mathrm{O}_{3}, \mathrm{Y}_{2} \mathrm{O}_{3}\right.$, $\mathrm{Ca}_{2} \mathrm{O}_{3}, \mathrm{Sb}_{2} \mathrm{O}_{3}$ )의 첨가량에 따른 비저항 (resistivity)의 변화를 나타내고 있다.

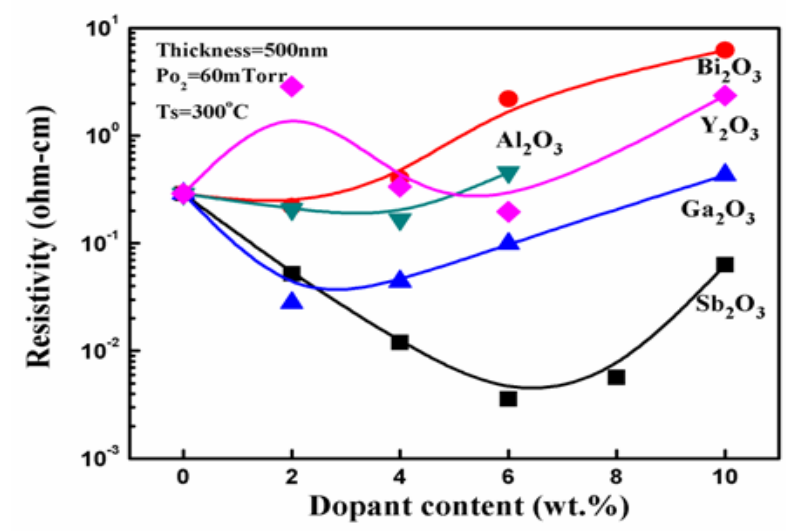

Fig. 1. Electrical resistivity $(\rho)$ as a function of trivalent content in the at $300^{\circ} \mathrm{C}$ in 60 mTorr of oxygen partial pressure.

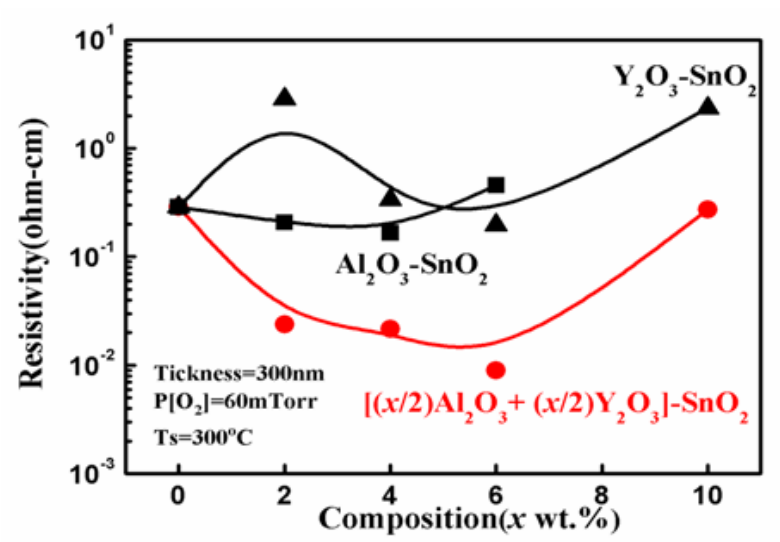

Fig. 2. Electrical properties for the $\mathrm{SnO}_{2}:\left(\mathrm{Al}_{2} \mathrm{O}_{3}+\mathrm{Y}_{2} \mathrm{O}_{3}\right)$ films grown on glass substrate with different thickness.

본 실험의 목표는 단순히 비저항을 낮추는 의도도 있었지만 이보다도 동시치환의 경우 양이온 자리 동시치환 효과를 가지면서 이에 이온반경 조절이 가 능하여 보다 낮은 비저항 특성을 가질 수 있다는 것 을 증명하고자 한 것이 실험의 목적이다. 따라서 본 조성이 가장 최적화된 동시치환 원소로 말할 순 없으 나 이론적 배경에 비추어 동시치환으로 보다 낮은 비 저항 특성을 유도할 수 있다는 것을 증명하고자 하는 것이다. $\mathrm{Al}_{2} \mathrm{O}_{3}$ 와 $\mathrm{Y}_{2} \mathrm{O}_{3}$ 는 다른 3 가 원소에 비해 조성 에서 가장 낮은 값을 보였기에 본 실험에서는 $\mathrm{Al}_{2} \mathrm{O}_{3}$ 와 $\mathrm{Y}_{2} \mathrm{O}_{3}$ 를 최적 동시치환 원소로 선택한 후 보강 실 험을 계속 수행하였다.

그림 2는 박막두께를 $300 \mathrm{~nm}$, 산소압력을 60 mTorr, 기판온도를 $300^{\circ} \mathrm{C}$ 하였으며 $\mathrm{Al}_{2} \mathrm{O}_{3}$ 과 $\mathrm{Y}_{2} \mathrm{O}_{3}$ 를 1 $: 1$ 의 비율로 혼합하여 총 첨가량을 $0 \sim 10 \mathrm{wt} \%$ 되게 하여 $\mathrm{SnO}_{2}$ 에 동시 치환한 후 $\mathrm{Al}_{2} \mathrm{O}_{3}: \mathrm{Y}_{2} \mathrm{O}_{3}-\mathrm{SnO}_{2}$ 박막 을 제작 후 비저항을 측정하였다. 측정결과 첨가량을 3 wt. $\% \mathrm{Al}_{2} \mathrm{O}_{3}$ 과 3 wt. $\% \mathrm{Y}_{2} \mathrm{O}_{3}$ 을 $\mathrm{SnO}_{2}$ 에 동시 치환하 였을 때 가장 낮은 비저항값 $\left(8.9 \times 10^{-3} \Omega \cdot \mathrm{cm}\right)$ 을 나타 냈으며, 이는 $\mathrm{Al}_{2} \mathrm{O}_{3}$ 과 $\mathrm{Y}_{2} \mathrm{O}_{3}$ 을 각각 치환했을 때 보다 더 낮은 값을 가지는 것으로 확인되었다.

그림 3 은 산소압력을 $60 \mathrm{mTorr}$, 기판온도를 $300^{\circ} \mathrm{C}$ 하였으며 $\mathrm{Al}_{2} \mathrm{O}_{3}$ 과 $\mathrm{Y}_{2} \mathrm{O}_{3}$ 을 $\mathrm{SnO}_{2}$ 에 동시 치환하였을 때 의 $\mathrm{XRD}$ 를 통한 결정구조로써 분석 결과 첨가량이 2 wt. $\% \mathrm{Al}_{2} \mathrm{O}_{3}$ 과 2 wt. $\% \mathrm{Y}_{2} \mathrm{O}_{3}$ 일 때 결정성이 나타나기 시작하였으며, $\mathrm{Al}_{2} \mathrm{O}_{3}$ 와 $\mathrm{Y}_{2} \mathrm{O}_{3}$ 의 첨가량이 3 wt.\% $\mathrm{Al}_{2} \mathrm{O}_{3}$ 과 $3 \mathrm{wt} \% \quad \mathrm{Y}_{2} \mathrm{O}_{3}$ 로 증가하면서 결정성이 향상되는 것으로 확인되었다. 하지만 그 이상의 첨가량 $5 \mathrm{wt} . \%$ 


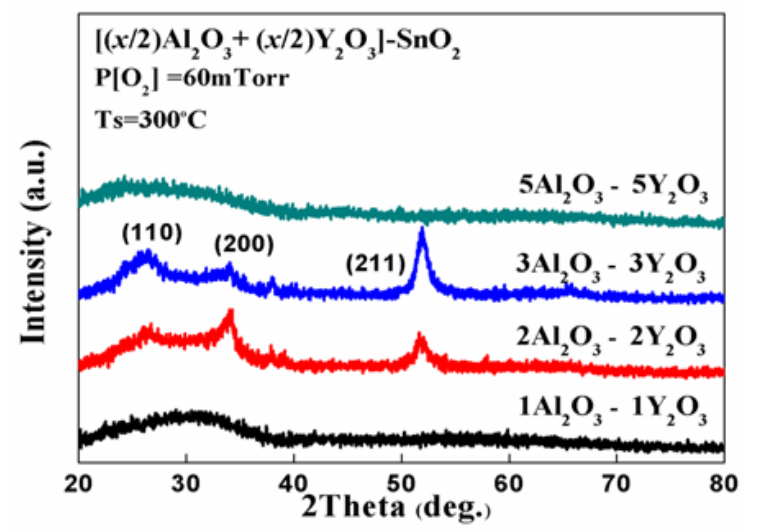

Fig. 3. $\mathrm{XRD}$ for the $\mathrm{SnO}_{2}:\left(\mathrm{Al}_{2} \mathrm{O}_{3}+\mathrm{Y}_{2} \mathrm{O}_{3}\right)$ films grown on glass substrate with different composition.

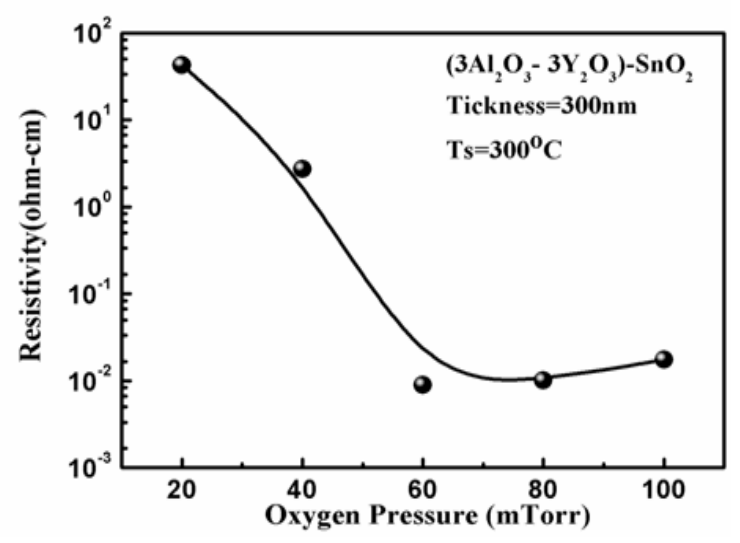

Fig. 4. Electrical resistivity $(\rho)$ for the $\mathrm{SnO}_{2}:\left(\mathrm{Al}_{2} \mathrm{O}_{3}+\right.$ $\mathrm{Y}_{2} \mathrm{O}_{3}$ ) films grown on glass substrate in different oxygen pressure.

$\mathrm{Al}_{2} \mathrm{O}_{3}$ 과 5 wt. $\% \mathrm{Y}_{2} \mathrm{O}_{3}$ 에서는 1 wt. $\% \mathrm{Al}_{2} \mathrm{O}_{3}$ 과 1 wt. $\%$ $\mathrm{Y}_{2} \mathrm{O}_{3}$ 처럼 비정질과 같은 $\mathrm{XRD}$ 결과를 나타내었으며 이와 같은 결정구조분석 결과는 앞선 그림 2 의 비저 항 분석결과와 동일한 경향을 나타내는 것을 알 수 있었다.

그림 4 와 그림 5 는 산소분압과 기판온도를 각각 변 화하여 비저항의 변화를 측정한 결과를 나타내었다. 산소분압의 변화에서는 박막두께를 $300 \mathrm{~nm}$, 기판온도 를 $300^{\circ} \mathrm{C}$ 로 하였으며 산소 분압이 $20 \mathrm{mTorr} \sim 60$ mTorr 사이에서는 비저항이 급격히 낮아지는 현상을 확인하였으며, 특히 $40 \mathrm{mTorr} \sim 60 \mathrm{mTorr}$ 산소분압 에서 비저항이 가장 큰 폭으로 낮아지는 것을 확인할 수

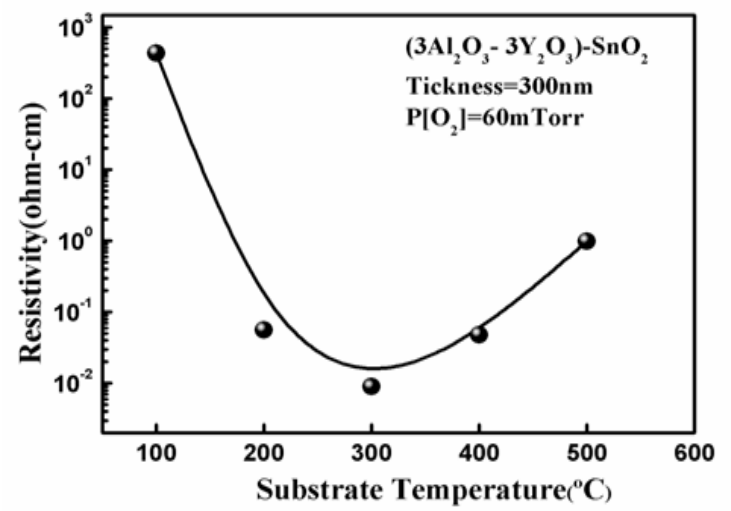

Fig. 5. Electrical resistivity $(\rho)$ for the $\mathrm{SnO}_{2}:\left(\mathrm{Al}_{2} \mathrm{O}_{3}+\right.$ $\mathrm{Y}_{2} \mathrm{O}_{3}$ ) films grown on glass substrate in different substrate temperature.

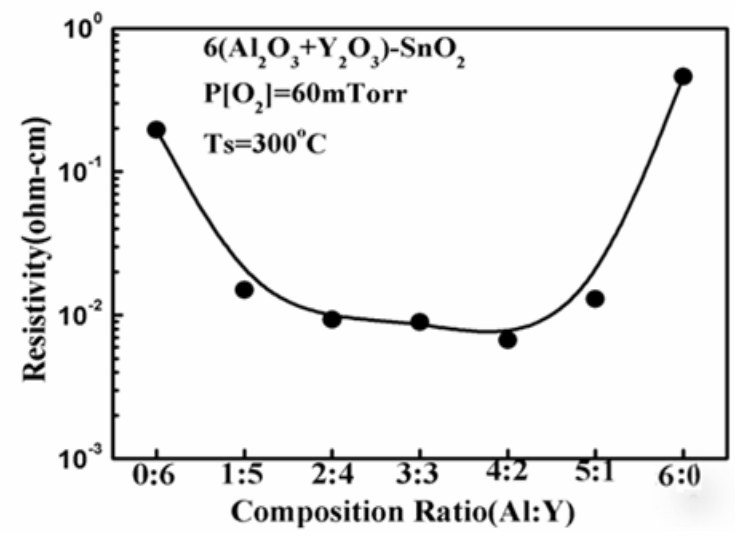

Fig. 6. Electrical resistivity $(\rho)$ electrical resistivity $(\rho)$ for the $\mathrm{SnO}_{2}:\left(\mathrm{Al}_{2} \mathrm{O}_{3}+\mathrm{Y}_{2} \mathrm{O}_{3}\right)$ films grown on glass substrate in different composition of $\mathrm{Al}_{2} \mathrm{O}_{3}$ and $\mathrm{Y}_{2} \mathrm{O}_{3}$.

있었다. 그리고 $60 \mathrm{mTorr} \sim 100 \mathrm{mTorr}$ 사이에서는 비저항이 큰 변화 없이 미세하게 증가하는 것을 보였 다.

기판온도의 변화에서는 박막두께를 $300 \mathrm{~nm}$, 산소분 압 $60 \mathrm{mTorr}$ 로 하였으며 $100{ }^{\circ} \mathrm{C}$ 일 때 가장 높은 비저 항을 나타냈었다. 온도가 증가함에 따라 $100^{\circ} \mathrm{C} \sim 30$ $0{ }^{\circ} \mathrm{C}$ 에서 점차 비저항이 낮아지는 것을 확인할 수 있었 으며 특히 $100^{\circ} \mathrm{C} \sim 200^{\circ} \mathrm{C}$ 사이에서 가장 큰 폭으로 비 저항이 낮아지는 것을 확인하였으며 기판온도 $300^{\circ} \mathrm{C}$ 일 때 가장 낮은 비저항이 가지는 것으로 확인되었으 며 그 이상의 온도에서는 다시 비저항이 점차 증가하 는 것을 확인할 수 있었다. 


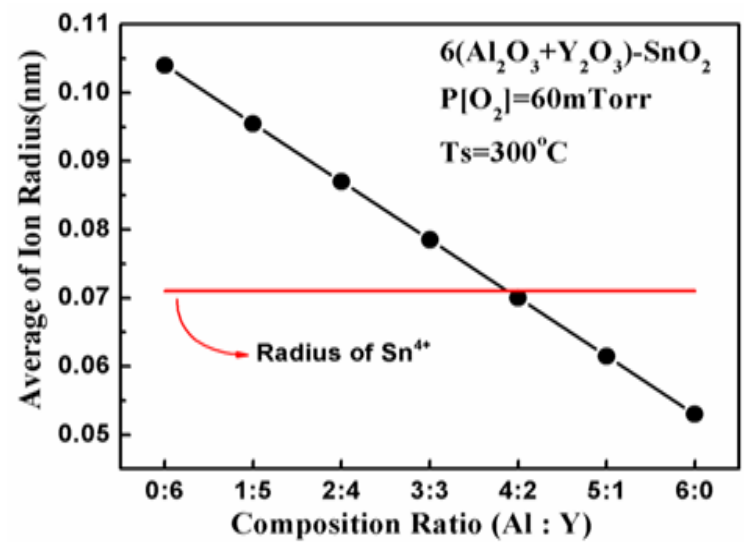

Fig. 7. Ion radius of $\mathrm{SnO}_{2}:\left(\mathrm{Al}_{2} \mathrm{O}_{3}+\mathrm{Y}_{2} \mathrm{O}_{3}\right)$ films grown on glass substrate in different composition of $\mathrm{Al}_{2} \mathrm{O}_{3}$ and $\mathrm{Y}_{2} \mathrm{O}_{3}$.

그림 6에서 최적 박막 증착 조건인 $60 \mathrm{mTorr}$, 기 판 온도 $300^{\circ} \mathrm{C}$ 에서 $\mathrm{Al}_{2} \mathrm{O}_{3}$ 과 $\mathrm{Y}_{2} \mathrm{O}_{3}$ 의 총 첨가량이 6 wt.\%로 고정시킨 후 $\mathrm{Al}_{2} \mathrm{O}_{3}$ 과 $\mathrm{Y}_{2} \mathrm{O}_{3}$ 의 비율을 각각 변 화하여 비저항을 측정한 결과로써 $\mathrm{Al}_{2} \mathrm{O}_{3}$ 과 $\mathrm{Y}_{2} \mathrm{O}_{3}$ 의 비 가 $4: 2$ 가 되었을 때 가장 낮은 비저항 $\left(6.7 \times 10^{-3} \Omega\right.$. $\mathrm{cm})$ 을 나타냈으며 $3: 3,2: 4,5: 1,1: 5,0: 6,6: 0$ 순 서로 비저항이 낮은 것을 확인할 수 있었다.

그림 7은 $\mathrm{Al}_{2} \mathrm{O}_{3}$ 과 $\mathrm{Y}_{2} \mathrm{O}_{3}$ 가 $\mathrm{SnO}_{2}$ 에 첨가되는 비율을 바탕으로 산소분압을 $60 \mathrm{mTorr}$, 기판 온도를 $300^{\circ} \mathrm{C}$ 로 하였을 때 도펀트의 평균 이온 반경을 계산을 하 면 $\mathrm{Al}: \mathrm{Y}$ 의 비가 $4: 2$ 일 때 $\mathrm{Sn}^{4+}$ 와 가장 유사한 것을 알 수 있었고, $0: 6,1: 5,2: 4,3: 3,4: 2,5: 1,6: 0$ 의 순서로 이온반경이 감소하는 경향을 나타내었다.

\section{4. 결 론}

$\mathrm{Al}_{2} \mathrm{O}_{3}$ 과 $\mathrm{Y}_{2} \mathrm{O}_{3}$ 을 $\mathrm{SnO}_{2}$ 에 동시 치환하여 이온반경을 주격자 이온 $\left(\mathrm{Sn}^{4+}\right)$ 과의 이온반경비를 유사하게 조절 함으로써 strain energy를 보다 감소시켜 고용영역을 확대하고자 하였다. $\mathrm{Sn}^{4+}$ 경우 이온반경은 $0.071 \mathrm{~nm}$, $\mathrm{Al}, \mathrm{Y}$ 첨가량이 $4: 2$ 비율일 때 이온반경이 $0.07 \mathrm{~nm}$ 확인되었으며 결론적으로 평균 이온반경이 유사한 것 으로 확인되었다. 이에 가장 낮은 비저항값인 $6.7 \times 10^{-3}$ $\Omega \cdot \mathrm{cm}$ 를 가지는 $\mathrm{n}$-형 투명전극이 형성되는 것이 확인 되었다.

\section{감사의 글}

본 연구는 지식경제부 및 정보통신산업진흥원의 대 학 IT연구센터 육성지원 사업의 연구결과로 수행되었 음(NIPA-2012-H0301-12-2009), 본 연구는 교육과학 기술부와 한국연구재단의 지역혁신인력양성사업으로 수행된 연구결과임 (2012H1B8A2026212).

\section{REFERENCES}

[1] Y. H. Jung, E. S. Lee, B. Munir. R. A, Wibowo, and K. H. Kim, J. Kor. Inst. Surf. Eng., 38, 150 (2005).

[2] C. Y. and C. H., Sol. Energ. Mat. Sol., C92, 530 (2008).

[3] T. Minami, MRS Bulletin, 25, 38 (2000).

[4] K. Ellmer, J. Phys. D: Appl. Phys., 34, 3097 (2001).

[5] J. F. Carlin, U. S. Geological Sruvey, Mineral Commodity Summaries (2006).

[6] Y. Wang, T. Brezesinski, M. Antonietti, and B. Smarsly, ACS Nano, 3, 1373 (2009).

[7] F. Rohlfing, D. Brezesinski, T. Rathousky, J. Feldhoff, A. Oekermann, T. Wark, M. B. Smarsly, Adv. Mater., 18, 2980 (2006).

[8] F. J. Yusta, M. L. Hitchman, and H,Shamlian, J. Mater. Chem., 7, 1421 (1997).

[9] T. P. Chow, M. Ghezzo, and B. J. Baliga, J. Elec. Trochem. Soc., 129, 1040 (1982).

[10] E. Shanthi, V. Dutta, A. Banerjee, and K. L. Chopra, J. Appl. Phys., 51, 6243 (1981).

[11] J. Bruneaux, H. Cachet, M. Froment, and A. Messad, Electrochemica Acta, 39, 1251 (1994).

[12] J. Springer, A. Poruba, and M. Vanecek, J. Appl. Phys., 96, 5329 (2004).

[13] M. N. Van Den Donker, A. Gordijn, H. Stiebig, F. Finger, B. Rech, B. Stannowski, R. Bartl, E.A.G. Hamers, R. Schlatmann, and G. J. Jongerden, Sol. Energy Mater. Sol. Cells, 91, 572 (2007).

[14] V. Hopfe and D. W. Sheel, Plasma Process. Polym., 4, 253 (2007).

[15] W. B. Jackson, N. M. Amer, A. C. Boccara, and D. Fournier, Appl. Optics, 20, 1333 (1981).

[16] D. Belanger, J. P. Dodelet, B. A. Lombos, and J. I. Dickson, J. Elec. Trochem. Soc., 132, 1398 (1985).

[17] A. M. K. Dagamseh, B. Vet, F. D. Tichelaar, P. 
Sutta, and M. Zeman, Thin Solid Films, 516, 7844 (2008).

[18] S. G. Ansari, S. W. Gosavi, S. A. Gangal, R. N. Karekar, and R. C. Aiyer, Journal of Materials Science: Materials in Electronics, 8, 23 (1997).

[19] K. H. Kim and C. G. Park, J. Elec. Trochem. Soc., 138, 2408 (1991).

[20] Z. M. Jarzebski and J. P. Marton, J. Elec. Trochem. Soc.,: ReViews and News, 123, 199 (1976).

[21] A. F. Carroll and L. H. Slack, J. Elec. Trochem. Soc., 123, 1889 (1976).

[22] H. Toyosaki, M. Kawasaki, and Y. Tokura, Appl. Phys. Lett., 93, 132109 (2008).
[23] A. Kurz, K. Brakecha, J. Puetz, and M. A. Aegerter, Thin Solid Films, 502, 212 (2006).

[24] S. W. Lee, Y. W. Kim, and H. Chen, Appl. Phys. Lett., 78, 350 (2001).

[25] D. Li, X. Fang, Z. Deng, W. Dong, R. Tao, S. Zhou, J. Wang, T. Wang, Y. Zhao, and X. Zhu: J. Alloys Comp., 486, 462 (2009).

[26] K. Tonooka and N. Kikuchi, Thin Solid Films, 515, 2415 (2006).

[27] A. M. K. Dagamseh, B. Vet, F. D. Tichelaar, P. Sutta, and M. Zeman, Thin Solid Films, 516, 7844 (2008). 